\title{
Organochlorine Pesticides in Three Fish Samples
}

\section{Rausan Zamir, Mosharof Hossain, Mohammad Shoeb, Mohammed Mosihuzzaman and Nilufar Nahar*}

Department of Chemistry, Dhaka University, Dhaka-1000, Bangladesh

(Received : 21 June 2012; Accepted : 24 December 2012)

\section{Introduction}

Use of organochlorine pesticides (OCP) is forbidden in Bangladesh, but evidences of the presence of OCP were found in the environmental samples (fish, dry fish, and poultry feed $)^{1-2}$ and through the food chain in human blood samples as well ${ }^{3-4}$. The cause may be illegal trafficking of banned OCP from neighboring countries where OCP are allowed to use in health sector and pilferage from large stockpiles of OCP in the three godowns of Bangladesh ${ }^{5}$. Fish is one the most suitable bio-concentrators to identify $\mathrm{OCP}^{6}$. In continuation of our work on OCP, we are now reporting residual level of DDT (1,1,1-trichloro-2,2-bis(4chlorophenyl)ethane) and its metabolites in three large sizes fish samples, Labeo rohita (rui), Katla katla (katla) and Pangasius pangasius (pangus).

\section{Methods and Materials}

Three fish samples, rui $(n=10)$, katla $(n=10)$ and pangus $(n=10)$ were purchased from Dhaka New Market, Polashi Bazar, Azimpur Bazar, Kaptan Bazar, Mirpur Bazar, Gabtoli Bazar and from the local markets of Chuadanga, Savar, Munshigonj and Gazipur districts (the average sizes of the fish samples were $\sim 2.5 \mathrm{~kg}$ ). The collected fish samples were washed in water, wrapped with aluminium foil and kept in a chilled box, transferred immediately to the laboratory and stored below $-15^{\circ} \mathrm{C}$ until analysis was carried out.

All the chemicals, reagents and solvents were analytical and HPLC grade (purity 99.99\%). Anhyd. $\mathrm{Na}_{2} \mathrm{SO}_{4}$ was heated at $200^{\circ} \mathrm{C}(4 \mathrm{~h})$ and cooled before use. Certified standard of OCPs were purchased from Dr. Ehrenstrofer GmbH, Augsberg-Germany. All glass apparatus were cleaned and dried at $250^{\circ} \mathrm{C}$, cooled and wrapped with Al-foil before use. Gas chromatograph (Shimadzu-17A) with an electron capture detector (ECD) was used for the analysis of $\mathrm{OCP}^{1-5}$. Injector and detector temperatures were set at $230^{\circ}$ and $240^{\circ} \mathrm{C}$, respectively. Separations were performed on quartz capillary columns (SUPELCO SPB-50 \& SPB-5; both of 30 $\mathrm{m} \times 0.32 \mathrm{~mm}$ i.d. $)$ at $130(1 \mathrm{~min})$ to $230^{\circ} \mathrm{C}(10 \mathrm{~min})$ and 5 ${ }^{\circ} \mathrm{C}$ per min (split ratio 1:76) where helium and nitrogen were used as carrier $\left(2 \mathrm{mLmin}^{-1}\right)$ and make-up gases, respectively.

\footnotetext{
*Author for Correspondence, e-mail: nilufarnahar@yahoo.com
}

\section{Extraction and clean-up}

Edible parts of the fish samples were extracted by solid disperssion method, cleaned up by conc. $\mathrm{H}_{2} \mathrm{SO}_{4}$ treatment and the cleaned extracts were analyzed by $\mathrm{GC}-\mathrm{ECD}^{7}$.

\section{Results and Discussion}

Limit of detection (LOD) (S/N; 3:1) and Limit of quantification (LOQ) (S/N ratio, 9:1) for DDT, DDE and DDD were found to be $0.39,0.39,0.50$ and $1.36,1.36$ and $1.5 \mathrm{ppb}$, respectively whereas recoveries for the three compounds were found 74,81 and $93 \%$, respectively. The standard calibration curves were linear with correlation coefficient $\left(r^{2}\right)$ 0.987, 0.985 and 0.997 for DDE, DDD and DDT, respectively.

Residue levels of $p, p^{\prime}$-DDT, $p, p^{\prime}$-DDD and $p, p^{\prime}-\mathrm{DDE}$ in rui, katla and pungus fish samples were found to be in the range 3-192, 3-24, 4-67; 3-511, 0-59, 2-109 and 5-78, 0-16, 1-28, ( (2DDTs; 10-279, 6-669 and 8-113) $\mathrm{ngg}^{-1}$ fresh fish samples, respectively which are below Maximum Residue Limits $(\mathrm{MRL})^{8}$. The percentage ratio of $\sum$ DDTs/DDT were found to be $0.59,0.68$ and 0.57 for rui, katla and pangus, respectively which indicated their recent and ongoing uses. Although the residue levels are below MRL, but the long term consumptions will accumulate in fatty tisues in human subjects, and will cause chronic toxic effects.

\section{Acknowledgement}

This work was jointly supported by the International Programme in the Chemical Sciences (IPICS), University of Uppsala, Sweden and Bose Centre for Advance Studies, University of Dhaka, Dhaka-1000.

\section{References}

1. Nahar, N., M.I.R. Mamun, R. Zamir and M. Mosihuzzaman, 2008. Analysis of Pesticide Residues in Some Local Fish and Vegetable, Dhaka Univ. J. Sci., 56 (2), 1-4.

2. Shoeb, M., N. Nahar, S. Mandal, H.M. Sarma, and M. S. I. Seraji, 2009. Nitrofuran antibiotics and organochlorine pesticides in Fish and Poultry Fish, Feed ingredients, and water samples collected from shrimp cultivation area, $J$. Bangladesh Chem. Soc., 22 (1), 1-8 .

3. Linderholm, L., K. Jakobsson, T. Lundh, R. Zamir, M. Shoeb, Nahar N, and A Bergman, 2011. Environmental exposure to POPs and heavy metals in urban children from Dhaka, Bangladesh, J. Environ Monit, 13 (10), 2728-34. 
4. Zamir, R, M. Athanasiadou, N. Nahar, M. I. R. Mamun, M. Mosihuzzaman and Å. Bergman, 2008. Persistent Organohalogen Contaminants in plasma from groups of humans with different occupations in Bangladesh, Chemosphere, 74, 453-459

5. Nahar, N., 2006. Survey \& research DDT and PCBs in food items and environmental samples, Department of Environment, Ministry of Environment and Forests, Government of Bangladesh.
6. Beyer, J., 1996. Fish biomakers in marine pollution monitoring evaluation and validation in laboratory and field studies, Academic thesis, University of Bergen, Norway.

7. Åkerblom, M., 1995. Environmental Monitoring of Pesticides Residues. Guideline for the SADC region, SADC ELMS monitoring Techniques Series 3, Maseru, Lesotho.

8. Alimentarius, C., 1993. Pesticide Residues in Food. Joint FAO/WHO Food Standards Programme, 2, Codex Alimentarius Commission 23. 